\title{
Osteosarcoma Arising in Paget Disease of Bone
}

National Cancer Institute

\section{Source}

National Cancer Institute. Osteosarcoma Arising in Paget Disease of Bone. NCI

Thesaurus. Code C6469.

A sarcomatous transformation of pre-existing Paget disease of the bone.

Osteosarcomas arising from Paget disease of the bone are high grade lesions and usually have a poor prognosis. 